with that treatment, but I lave not reached any final conclusions in regard to it. However, I shall publish all my experience in phototherapy in the near future.

Heroin for the Cough.- And now one word about the bronchial cough in these cases. Among the most distressing symptoms of laryngeal tuberculosis is the concomitant bronchial cough, which is often of a most harassing character, and contributes materially to the patient's exhaustion by preventing rest at night. For its relief we were formerly forced to rely on morphin and codein, although both these drugs left much to be desired. Aside from its well-known after-effects, morphin is particularly objectionable because of its tendency in many instances to disturb the digestive organs, and thus impair the patient's appetite. Codein, while in general preferable to morphin. has the disadvantage of being uncertain and unreliable in action. The introduction of heroin has been a decided advance in the treatment of cough in phthisical cases. In an article on the "Treatment of Dysphagia and Cough, Especially in Tuberculosis,"5 I have reported my preliminary results with this new drug, which were most farorable. Since then its continued use has given very satisfactory results. The irritable congh in tuberculous patients frequently yields to the administration of horoin, and this occurs in cases in which both morphin and codein have proved completely inefficient. The action of heroin in modifying the respirations by diminishing their frefuency and increasing their force, renders the breathing much easier. Aside from some lassitude and slight constipation, I have nerer observed the least after-effects from heroin, and as mr experience relates now to sereral hndred cases in dispensary and private practice, I feel convinced that the drug is perfectly safe when used with ordinary precautions. In several instances, however. the constipation was sufficiently marked to call for the administration of laxatives, such as extract of cascara sagrada and aloin. My observations in this respect are in accord with those of Einhorn, Manges, and others, who have reported their results. Although we can not be sufficiently conservative in admitting to our confidence any new remedy which claims our attention, my experience with heroin has now been so extensive that I have no hesitation in assigning to it a prominent place in the list of medicaments for the relief of cough.

In summing up my experience with tuberculous laryngitis, $I$ should like to emphasize the fact that there is a pathologic condition which might justly be called pretuberculous laryngitis. This ought to be treated with great care in every consumptive patient. Regarding the treatment of laryngeal tuberculosis we are nowadays fortunate enough to give great relief to by far the majority of these patients. Of these remedies which are so potent, I should like to mention: 1 . The saccharated suprarenal gland for the induction of preliminary local anesthesia. 2. The menthol-orthoform emulsion for the production of a longer local anesthesia, and for its curative effects. 3. Olive, almond or sesame oil for the relief of the dysphagia. 4. Phototherapy. 5. Heroin for the relief of bronchial cough. Lactic acid ought to be dispensed with as antiquated and barbarous torture to the patients. Finally, I would like to say that here is a large field for further fruitful investigations in which every one ought to be interested; and the more we work in this field the more relief we shall give to our patients and the more cures we will effect.

5. Phila. Med. Jour., March 25, 1899.
DISCLSSTOX.

Dr. EMIL MaYer, New York City-I would like to endorse the use of orthoform for this particular condition, and would call attention to the preparation with the white of the egg, for which I believe Dr. Freudenthal is responsible; that makes a very stable preparation and one that is valuable. I have found orthoform mixes very well with some of the liquid vaselin preparations, such as benzonol, and $I$ have used that sometimes when the emulsion was not to be obtained. It may be said also that orthoform is not only of use for the painful deglutition that is associated with the tubereular trouble, but also in those conditions following operations. Nothing will give your patient so much eomfort after a tonsillotomy as this emulsion.

Dr. Holbrook Curtis, New York City--One thing brought out was the use of the suprarenal extract. I reported, a few months ago, my first case, and I have now three using the extract for painful deglutition, and with most remarkable results. It has at the same time a most excellent effect on the edema. I have also used the suprarenal extract in quinsy and edema of the glottis with remarkable effect. I think it will prove of great value.

DR. RICIAARDS-I would like to ask Dr. Freudenthal whether this solution can be sprayed through an atomizer.

Dr. Frevdenthal-Not this solution; I use it with : 11 ordinary laryngeal syringe.

Dr. W. Frecdentinal--I am giad Dr. Mayer had the sam experience as I did, and I shall try this solution in benzonol. which $I$ think will be very good. I have not used this emulsion for tuberculous cases alone, but $I$ have used it in syphilitic cases as well. In a case that came to me recently I injected this solution for severe pain, and the patient experienced almost immediate relief. The effect on edema is very good. which is due largely to its action as an astringent.

\section{TREATMENT OF ATROPHIC RHINITIS BI ELECTROLYSIS.}

\section{AXD SOME EXPERIMENTS TO DETERMINE THE EFFICIENCY OF NEEDLES OF DIFFERENT METALS. * \\ CAROLUS M. COBB, M.D. \\ BOSTON, MASS.}

Atrophic rhinitis has been the bane of the rhinologist since the diseases of the nasal mucous membrane began to receive special attention. It is not at all surprising that the disease remained incurable during the time in which the diseases of the upper air-tract were treated by the ophthalmologist or otologist as a side issue to what he considered of more importance. Not only this, but most other diseases of the nasal cavities were considered incurable, not alone by the laity, but by the profession as well. This is hardly to be wondered at when we remember that the treatment of the different diseases of nasal cavities was much the same and consisted in the use of a spray and the application of a solution of nitrate of silver to the surface of the nasal mucous membrane or to such part of it as could be easily reached. The patients were given a spray to use at home, and I think that they accomplished as much by its use as was accomplished by the physician himself. These sprays were usually composed of varying combinations of alkalies, and each specialist had a formula of his own which he was only too apt to think was a specific. In the use of watery sprays the fact that the nose was made for the passage of air and not for water, seems to have been overlooked. That these sprays gave temporary relief, but did not cure, was at last recognized by all, and while it may be necessary for the physician to occasionally use a spray for cleansing purposes, I am inclined to think it is well for the patient to cleanse his own nose as a rule.

The medical sprayer, if you will allow the expression, did not cease to exist when he found that sprays did not

* Presented to the Section on Laryngology and Otology, at the Fifty-first Annual Meeting of the American Medical Association, held at Atlantic City. N. J., June 5.8. 1900. 
cure nasal disease, but the argument was changed and he frankly admitted that the so-called catarrhal diseases were incurable in this climate-it made no particular difference where he might be, one place was too windy, another too dusty; another too cold, in another the climate was too variable, etc., ad nauseam-but if the patient will use this spray, the disease will be prevented from growing worse. This advice was given to all patients, but more especially to those who suffered from one of the most horrible of the diseases of the nasal cavities, horrible not from disfigurement or from danger to life, but from the persistent and almost unbearable odor which accompanies it. In this disease it would seem that a spray might be of some use, and it undoubtedly is of some slight benefit, but there is usually not enough of it in volume or force to dislodge the crusts, and if the patients rely on the spray for treatment they are condemned to live with this disgusting odor always with them, an object of aversion to themselves and avoided by their friends. Fortunately they early lose the sense of smell and in this way are relieved of a part of their burden.

To cure this disease confers as great an obligation on these patients and their friends as the cure of any other loathsome disease. With the zeal born of specialism, earnest, intelligent men have set themselves the task to accomplish this object, and while much yet remains to do, we have already succeeded to a great extent in curing the disease. As is often the case, our treatment has outrum our knowledge of etiology, and while we are already able to cure a large proportion of the patients, we do not know as yet what part the bacteria play in the production of the disease, neither do we know how much the disease may depend upon or be influenced by the general systemic condition or by the presence of in nasal empyema, or what part the cephalic index may play as a predisposing cause. It has not yet been definitely settled whether the bacteria which are found in such numbers in the nasal cavities in cases of atrophic rhinitis are of primary or of secondary importance, and as I have nothing new to offer, I will not take rour time with a review of the opinions of others on the subject. I do wish to call your attention to the importance of a close differential diagnosis between true atrophic rhinitis and disease of the accessory sinuses. That many of the cases which are diagnosed as atrophic rhinitis have their origin in a nasal empyema there is not the slightest doubt. I have seen so many cases with all the symptoms of a typical atrophic rhinitis and have found after the crust formation was stopped that there was a discharge from a nasal empyema, that I feel that the recognition of this condition can not be insisted upon too strongly. Whether the nasal empyema-when it exists-is of primary or of secondary etiological importance is a question to be decided by the physician in each case, but if we expect to be successful in treating these cases, the nasal empyema must receive attention. The diagnosis of this complicating disease is easily made. If after the nasal cavity is thoroughly cleansed we find pus appearing within a short time in one or both the pathways of the drainage from the accessory sinuses, we may feel reasonably sure that we have to deal with a collection of fluid in one or more of the sinuses. The enlarged middle turbinate which is so often found in cases of atrophic rhinitis may be the cause of a nasal empyema by interfering with the drainage from the accessory sinuses, or the cell which is contained in this enlargement may be the site of the emprema. If we are satisfied that we have to deal with a nasal empyema as a complication of the atrophic condition, we should not hesitate to remove enough of the turbinate to improve the drainage. I have removed the anterior wall of the enlarged middle turbinate, with the most gratifying results, in cases where I had reason to believe that the empyema was the cause of the crust formation. It is always well to examine very thoroughly for a possible sinus involvement those cases which follow scarlet fever, measies, typhoid fever, diphtheria and erysipelas. If a nasal empyema is found to exist it is unnecessary to add that it should be treated by thorough drainage. What proportion of the cases of atrophic rhinitis depend upon sinus disease is very hard to determine; from my own experience I should think fully 50 per cent. have this origin or are seriously influenced by this complication.

After this brief review of the most important complication of the disease, we will next consider its treatment by electrolysis. In 1895 , at the meeting of the Belgian Laryngologists and Otologists, held in Brussels, Cheral announced that he had been able to cure 91 per cent. of his cases of ozena by interstitial electrolysis. This statement was received with more or less incredulity by the other laryngologists, and the method was tested icry thoroughly by Bayer, of Brussels, and by many others during the next year. Bayer, who was at first skeptical, after a year's experience reported favorably, as did many others. Among the enthusiastic advocates of the method are Brindel, of Bordeaux; Rethi, of Vienna, and McBride, of Edinburgh. All observers unite in the report that there is an immediate and decided lessening of the odor and a marked decrease in the amount of crusts and that they are easily removed from the nose. The improvement often occurs after the first treatment and it rarely requires more than five or six applications to accomplish all that can be hoped for. Cheval reports that 70 patients were cured in a single sitting, 12 required several, and 3 were still under treatment. One case was improved, but not cured after six sittings. One of the most striking results of the treatment is the disappearance of all odor. This often oceurs on the day of the first treatment. and it may not return for months, even though the crust formation does not entirely cease. The important question then is, For how long a time does this improvement continue? This will, of course, vary in individual cases, and may he from a few months to a year or more. McBride exhibited two cases before the British Medical Association. in 1898, in whom the improvement had lasted for a rear without any return of the odor and with but slight tendency to crust formation. Brindel, while noting improrement in all, admits that it is not permanent. In the ten eases which he reports, at the time of writing there was no return of the odor or erusts, and ther had been under treatment as follows: 1 , eleven months previously; 3 , ten months; 1 , nine months: 1 , eight months; 2 , seven months; 1 . five months; 1, three months. Of these only two could be said to be cured, that is, in which the atrophy had entirely disappeared. Hajol: and Gdiari both have protested against considering these cases as cured when the odor and crusts have only been relieved, hut no anatomical changes have taken place. Hendelsolm also cantions against placing too much reliance on the nermanence of the cure.

If we seck for an explanation of the effect of the galvanis colrent upon the tissues in cases of atrophic rhinitis, we find various opinions expressed by different writers. Baver attributes it to the effect unon the nervous sretem. Gautier and Tavier to the reposition of a 
copper salt in the tissues, Delavan to the mechanical stimulation of the tissues. If we investigate the action of the galvanic current upon living tissue we shall be able perhaps to explain the effect which it has in these cases. In doing this we must of necessity go over much ground that is perfectly familiar to you all. It may be well in the beginning to make this statement: that the passage of the electrical current, as we know it, is always destructive to cell life: that it is always and everywhere a life-destroyer and not a life-giver. If the destruction is not carried too far it may act as a stimulant and it may also have a remedial action by liberating certain elements from the tissues through which it passes or by depositing remedies in them. It is not material whether we consider the change in the cell by which this destruction is accomplished as chemical or mechanical. The galvanic current outside of the batterv passes from the positive to the negative pole and when passing through living tissue carries along with it a certain amount of the basic elements of the cells, thus destroying their chemical structure. The removal of the base from the salt liberates those elements which are known as the acid-forming, and these being liberated by the current appear at the positive pole. Oxygen and chlorin are the elements that appear at the positive pole, with perhaps others in infinitesimal quantities, and they unite with the metal of the electrode and form a salt which may in turn be decomposed and the metal carried along with the current. It is evident that many things may have an influence over this electrolytic action. The first to be considered is the resistance of the tissues, which, of course, varies for the different structures through which the current passes, and while we are not able to estimate this for different tissues and perhaps different individuals, we do know that all of the current does not follow the path of least resistance; for example; if we have two substances, one of $1 \mathrm{ohm}$ resistance and the other of 1000 ohms, the current will pass through the higher resistance in inverse proportion to the lesser. We have next to take account of the diffusion of the current. This is probably about equal to the diffusion which takes place when a current passes through the earth; at least we have no better way of estimating it. An electrical current passing through the earth between oints one mile apart is diffused about 1100 feet each side from the center, or a lateral diffusion of rather more than one-third of the linear distance, and forms an almost perfect ellipse. There is a large conducting area for the current as soon as it leaves the needle, and, further, the current does not all pass from the needle on the side toward the other pole, and in the use of electricity in the treatment of disease it is rarely possible to place the two poles in the most favorable position to obtain least diffusion. It would seem to follow from this that the best results would be obtained when it was possible to concentrate the current, and this has been the result of experience in other branches of medicine.

After this brief allusion to some of the factors which influence electrolytic action in the tissues of the buman body, we will now consider the direct effect when a positive electrode of copper or other metal is used. If a copper needle is used for the positive pole: we should expect to have formed an oxygen and chlorin compound of copper, and this was the salt that Cheval and Bayer found, by chemical analysis, deposited on the positive pole. If another metal is used-with the exception of platinum, which is not affected by the gases liberated by the electrical current-we should get a salt with the metal used as a base. It has been claimed that the oxychlorid of copper is soluble in the lymph plasma, and some writers think that the beneficial results are obtained by the diffusion of this solution of the oxychlorid of copper through the tissues. We will speak of the solubility of this salt in connection with the inquiry into the amount of copper salts which may be obtained by electrolysis. It is interesting to inquire how much of this salt is deposited in the tissues during an ordinary treatment by electricity. According to Park Benjamin, one ampere flowing for one hour would liberate $11 / 10$ grams of an -ic salt, or $23 / 10$ grams of an -ous salt. It is quite probable that the salt formed in the tissues is a mixture of the two, and we will call it, speaking roughly, 20 grains of the combined salt. Twenty milliamperes, which is a very liberal dose of electricity; would therefore liberate one-fiftieth of 20 grains in one hour, and in ten minutes, the usual length of the sitting; one three-hundredth part of 20 grains or one-fifteenth part of 1 grain. To deposit 1 grain of a mixed salt of copper in the tissues would require one hundred and fifty minutes, or two and onehalf hours. These figures are, of course, not absolutely accurate, but are approximately so. In this connection it is well to call attention to the question of the solubility of the oxychlorid of copper which is found deposited upon the positive pole. In Roscoe's chemistry several oxychlorids are given. He notes the most common one, which is known in commerce as Brunswick green. The oxychlorids are evidently varying mixtures of the oxid and chlorid of copper, which would, in the presence of a saline solution like the lymph-plasina, break up and the chlorid salt would be dissolved, the oxid remaining in an undissolved condition. The fact that Cheval was able to remove enough of the oxychlorid of copper from the copper needle for chemical analysis would seem to indicate that the salt which is formed upon the surface of the copper needle is insoluble. It will be seen from the varying chemical and electrolytic conditions which may infiuence the deposition of a salt of copper that it is manifestly impossible to determine the amount which would be left in the tissues during an ordinary treatment by electrolysis, but we may be sure that under the most favorable conditions it would be no more than the amount which I have given, and it is probably less.

It does not seem as though the deposition of an infinitesimal amount of a mixed salt of copper in the tissues could produce the immediate and lasting results which follow the interstitial application of the galvanic current; and while it is not claimed that even the small amount of copper which it may be possible to deposit possesses no remedial properties, I have not been able to detect any difference in the results when either copper, silver, steel or platinum needles were used as the positive pole, or when both poles were of the same metal. I will not weary you by giving any detailed case histories. but will simply give the summary of the cases treated: Whole number of cases treated, 15; those in which the nasal empyema was of paramount importance, 8 ; number treated by copper and platinum, 2 ; by steel and platinum, 1 ; by silver and platinum, 2 ; by platinum and platinum, 2. I took the cases in rotation from my clinic and private practice, and I am fortunate in being able to report an equal number treated by the different electrodes, except the steel. I have not included those cases where the sinus disease predominated, because I not only used electricity. but improved the drainage as well, and in some of the cases repeatedly 
washed out the affected sinus. I do not feel that it would add to our knowledge of the value of electrolysis as a remedial agent in the treatment of atrophic rhinitis to include the good results obtained by measures directed to the relief of the nasal empyema. Of these seven cases of atrophic rhinitis, four were relieved of the odor and crust formation in one sitting, two in three sittings, and one in five. Two of them have remained free from odor and nearly free from crust formation for fourteen months, three for eleven months, one for eight months, and one had a return in a little over two months. The cases of nasal empyema were all very much benefited by the improvement in the drainage and the washing out of the cavities involved, but, as often occurs in the treatment of nasal empyema: the discharge was not entirely stopped in all of them. There is one point that should not be neglected, namely, that the improvement in the crust formation may improve the drainage from the accessory sinuses to such a degree that the nasal empyema which is an accompaniment, if it be not a cause of the crusts, is made permanently better.

I have gone very fully into the question of the deposition of copper in the tissues because $I$ believe it is well to know, when it is possible to do so, to what to ascribe the results which we obtain by any method of treatment. It now remains for us briefly to consider the question of the mechanical stimulation of the tissues and the effect upon the nervous system of interstitial electrolysis. The mechanical effect of the passage of the galvanic current through the tissues of the body may, for all practical purposes, be considered as nothing. Even if the current produced decided mechanical effect. this would not explain the results obtained by this method of treatment, for it is a well-known fact that other forms of mechanical stimulation have to be repeated at short intervals and for a considerable length of time; for instance, those who use vibratory massage in the treatment of atrophic rhinitis recommend that it be used every other day for three months, and then at longer intervals for several months more. There is every reason to believe that the galvanic current is an irritant to the nerves when it is brought in contact with them, but this irritation lasts practically only so long as the contact exists and it hardly seems possible that the application of the galvanic current would produce such lasting results. I am very well aware that the use of electricity is vaguely supposed to be beneficial in the treatment of nervous diseases, but I think that I am stating what is the general opinion of the leading neurologists when $\mathrm{I}$ say that, with one exception, the use of electricity is confined to diagnosis and not to treatment. The exception is the use of the faradic current in the treatment of some forms of muscular atrophy and the unanimity of opinion in regard to its use shows very conclusively that the faradic current is not of benefit in other conditions. The action of the faradic current has been defined as a mechanical massage, and this definition explains the results obtained by its use. If the action of the galvanic current in cases of atrophic rhinitis can not be attributed to any of the theories given, to what then is it due? If we go back to the explanation of the effect produced by the passage of the galvanic current we shall find that it breaks the chemical combination of the cell by its power to attract the basic elements and that they appear at the negative pole and that it repels the elements that are known as the acidformers and that they appear at the positive pole. The effect of a current which produces therapeutic results must be the same, only to a Jess degree, as that which is produced by the larger volume of current. If the destruction of the tissues of the body by the galvanic current is mechanical, then the therapeutic effect is the result of mechanical action, but I think no one claims that this is so. As I said earlier in this paper, the passage of the electrical current always produces the same result, the destruction of the cells, and this is only modified in degree, but not in character. by the amount of the current which passes, and by the force which drives it through the tissues. Between the large volume of current which produces extensive destruction of tissue and the very weakest, which is practically inert, lies the therapeutic use of the galvanic current. The action of the current is probably mostly confined to the soft parts, as the periosteum is a poor conductor of electricity. In the chemical destruction of the cells of the soft parts, the weakest cells are destroyed first, and this occurs in two ways: 1 , by the direct action of the current, and 2 , by the action of the acid-forming elements which are liberated around the positive pole. That the bacteria are also destroyed by the same action, the examinations of Bayer would seem to indicate, as he found that the number of colonies was very much reduced after treatment by electrolysis. The source of the oxygen and chlorin which are liberated around the positive pole is very largely the lymph-plasm; this is composed of over 90 per cent. of water, holding in solution albumin, fibrin, fatty matter, extractive matter and salts of sodium, potassium, calcium and magnesia. Of these various salts, sodium chlorid occurs in the greatest quantity, being 65.2 per cent. of the inorganic salts. From this brief review of the chemical composition of the fluid upon which the galvanic current must have the greatest effect, it will be readily seen from what source the oxygen and chlorin are obtained which are liberated around the positive pole. The water and the chlorid of sodium are broken up into their constituent elements by the action of the electrical current. If an electrode of platinum is used on the positive pole the oxygen and chlorin thus liberated are free to unite with the tissues; that they remain free in the tissues or that they escape does not seem probable when we remember the avidity with which these elements unite with others to form new combinations. While these substances are formed in minute quantities, still the effect may be, and undoubtedly is, considerable. The destruction of the cells and the liberation of oxygen and chlorin around the positive pole, which unite with the other elements to form new combinations that may be, temporarily at least, acid in reaction, in my opinion, is the explanation of the results obtained in the treatment of atrophic rhinitis by interstitial electrolysis. The effect is local, and in some cases immediate, the odor and crust formation often disappearing on the day of the first treatment; and coincident with this result is the change in the character of the secretion which, from being ropy and sticky, becomes liquefied and easily removed. This would tend to prove that there was a change in the chemical reaction of the tissues, or at least of the secretion, produced almost at once.

Many of the writers advise placing the needle of the negative pole beneath the mucous membrane of the septum; I do not consider this a safe procedure, for the reason that the sodium and potassium which are liberated around the negative pole are active escharotics and are liable to cause the destruction of considerable tissue, and may even cause perforation of the septum. There can be no doubt that we have in interstitial electrolysis a remedial agent of undoubted efficacy and that 
we may confidently expect from its use, in a large percentage of the cases at least, that the odor will cease, that the crust formation will be lessened, that the nasal mucous membrane will become moist and healthy in appearance, and that the secretion will become liquefied and lose its ropy, sticky character, and that these results will last for several months. It is needless to add that this is a more favorable showing than can be secured by any other known method of treatment. Electricity will not stop the discharge when this depends upon a nasal empyema, although it may have a beneficial effect upon the crust formation even in these cases; neither will it stop the odor when that depends upon the same cause. The conclusions to which I wish to draw your attention are:

1. Electrolysis has a curative action in atrophic rhinitis in so far as it stops the tendency to crust formation and the odor, in typical cases.

2. It does not stop the discharge or the odor if these are caused by nasal empyema.

3. That better results are obtained if the needles are placed comparatively near together.

4. That it makes no difference in the result what metal is used for needles, and it therefore follows that the diffusion of the copper salt is evidently not the curative agent.

5 . That the improvement in the condition of the nasal mucous membrane is most noticeable in the area around the positive pole.

6. That this improvement is probably due to the liberation of oxygen and chlorin, and the chemical change resulting from the presence of free oxvgen and chlorin in the tissues or the acid reaction produced thereby.

\%. That the needle of the negative pole should not be placed beneath the membrane of the septum.

I wish in closing to acknowledge my indebtedness to Dr. C. L. Sopher, of Wakefield, Mass., for his valuable assistance in collecting electrical data for this paper.

4]9 Boylston Street.

\section{DISCUSSION.}

DR. J. F. Gul, Harrisburg, Pa.-I was very much interested listening to Dr. Cobb's paper this morning. There is one thing he did not mention, that is, the unpleasant effect following the application of the electric current in the treatment he mentioned. Such effects are sometimes even more than un pleasant. I have personally seen this method tried and violent headache follow its application. I have seen very decided earache, and I have heard of decided syncope following the application of the current. In regard to the statisties attend ing this method of treatment. some of them are fallacious, for I personally know of cases that have been reported as cumd. and in which the physician has spoken in the highest term of the cure, that have relapsed in a very short time after the publication of the paper reporting them. Undoubt edly there is very much in the treatment, and I think I express the opinions of some of the other members of the Associatrov when I say I would like very much to hear a little more of the detail of the application of this method of treatment.

Dr. EDward PxNchor, Chicago-A good idea is that of having the patient attend to the cleansing part himself. I have done this, and am not afraid of having the patient use the douche twice a day, at first, perhaps, with a solution of phenol, and afterward with bicarbonate of soda, a teaspoonful to a pint. I also insist on his sniffing, every hour, a smal quantity of an alkaline solution, perhaps a one-half strength of the Dobell solution. In this way I have had no trouble in controlling the ozenous condition in atrophic rhinitis or in sinus disease. In connection with the atrophy, there is almost invariably present a hypertrophic condition of the middle turbinal upon the same side, and I have had very satisfactory results by early surgical treatment of such hypertrophied body. One thing which keeps up the condition of atrophy is the fact that there is an increased current of air in the low part of the nose, as it can not circulate in the upper part of the nose owing to the ocelusion thereof.
DR. C. M. CoBB, Lynn, Mass.-In regard to the strength of current and the details and unpleasant: symptoms that may result, and last but not least the duration of the cure, no one claims that these cases are permanently cured. In many instances they will stay in a reasonably comfortable condition for months. If they have been using any wash or cleansing spray at all they are very likely to keep using it, and that will often deceive you as to how much you have done. I invariably tell them to do nothing with the nose, that they may blow the crusts out, but that they should not use any spray. The treatment simply prevents any secretion sticking to the mucous membrane. Whether there is just as much secretion, or whether there is more I can not say, but it does not stick and form crusts. I use a platinum needle, which is not easily affected and is easily kept clean, and does not form any oxid or other salts. One little point is that you must keep the needles apart in their course, for if you get a short circuit before the current gets into the tissues you will not get any effect. I use a rheostat like the one used by dentists. I never use an amperemeter because it is not possible for the instru ment-makers to make an accurate milliamperemeter at the price they charge for them. They are approximately correct, that is, some of them are and some are not. But if you have a rheostat so you can control the current. and then turn the current on until the patient is sensible of it you will not be likely to use too much current and cause headache. Another thing, if you introduce the needles into the bone of the niddle turbinated you are much more likely to give a shock to the patient. I think the nasal speculum of hard rubber is a great advantage. I have a patient under treatment, and when he asked why I did not use the battery on the other side I told him that my battery was out of order. He perhaps think. that it is a long time being fixed, but the truth is, I wanted to see how he would do without the use of the battery. You know some believe that the treatment affects not only the side to which you apply the current, but also the other side and the pharynx as well. I do not think that this is true. In the casc I have mentioned the man has one side comparatively comfortable, while the other side, to which the current was not applied, is about the same as it was before. Dr. Pynchon mentioned hypertrophy of the middle turbinated. In those cases I remove the anterior part of the middle turbinated. and it is wonderful how much of the atrophy supposed to exist in the lower turbinated disappears. The nose becomes moist and the patient is more comfortable. It is not necessary in these cases to remove the whole turbinated, but if you will cut a good sized section out of it you will improve the case in every way.

\section{THE NATURE AND TREATMENT OF VERTIGO.*}

\section{J. LEONARD CORNING, A.M., M.D., LL.D. NEW YORK CITY.}

Among the various consequences of organic and functional disturbance of the nervous system with which we are called upon to deal. what is technically known as vertigo is surely one of the most common. Often insidious in its advent, obscure as to ultimate pathologv, in its treatment baffling, it has come to be regarded as a most slippery adversary, a kind of ignis fatuus of the clinic, at the view of whose antics and illusive wavs erudition and experience stand aghast.

Yet despite the unsatisfactory condition of present knowledge, there is no denying the eminent practical importance of the subject. Consider for a moment the amount of apprehension and annoyance caused by the symptom itself; then its frequency, as an accompaniment or sequence of the most disparate pathological conditions, and you will concede, I think, that a warrant is provided, sufficient to justify a careful sifting of available data, an analysis of which may incite, perhaps, to the formation of a more consistent concept of the phenomenon itself, and hence to more rational management.

Besides the more common forms of vertigo described in the books: that which accompanies disorders of the

* Presented to the Section on Materia Medica, Pharmacy and Therapeutics, at the Fifty-first Annual Meeting of the American Medical Association, held at Atlantic City, N. J., June 5-8, 1900. 